\section{The 11-year follow-up of the 1993 Pelotas (Brazil) birth cohort study: methods}

\author{
A visita de 11 anos da coorte de nascimentos de \\ Pelotas, Rio Grande do Sul, Brasil, 1993: métodos
}

Cora Luiza Araújo 1,2

Ana M. B. Menezes 1

Maria de Fátima A. Vieira 1,2

Marilda B. Neutzling 2,3

Helen Gonçalves 1

Luciana Anselmi 1,4

Samuel C. Dumith 1

Pedro C. Hallal 1,3

\footnotetext{
1 Programa de Pós-

graduação em Epidemiologia

Universidade Federal de

Pelotas, Pelotas, Brasil.

2 Faculdade de Nutrição

Universidade Federal de

Pelotas, Pelotas, Brasil.

3 Programa de Pós-graduação

em Educação Física,

Universidade Federal de

Pelotas, Pelotas, Brasil.

4 Faculdade de Medicina,

Universidade Federal do Rio

Grande do Sul, Porto Alegre,

Brasil.

Correspondence

P. C. Hallal

Programa de Pós-graduação

em Epidemiologia,

Universidade Federal de

Pelotas.

Rua Marechal Deodoro 1160,

Pelotas, RS

96020-220, Brasil.

prchallal@gmail.com
}

\begin{abstract}
The aim of this study is to describe the methodology of the 2004-2005 follow-up visit of the 1993 Pelotas (Brazil) birth cohort. All children born in Pelotas in 1993 and whose mothers lived in the city at that time were eligible to be enrolled in a longitudinal study. Between July 2004 and March 2005, all cohort participants were sought for a follow-up visit. Several strategies were used to help trace cohort members, including a census of the city's schools and a census of all households in the municipality. The Mortality Information System was monitored in order to identify deaths among cohort members. Of the 5,249 cohort members, 4,452 were interviewed in 2004-5. When added to the 141 deaths, these represent $87.5 \%$ of the original cohort. In spite of the logistic and financial difficulties, it is possible to carry out prospective studies with long-term follow-up in the Brazilian context.
\end{abstract}

Methodology; Prospectives Studies; Cohort Studies

\section{Introduction}

Despite the known importance of cohort studies to further our understanding of the determinants of the health-disease process, studies using this methodology are still scarce in medium or lowincome countries. One of the reasons for this is the high cost of this type of study, which necessarily involves active search for enrolled participants during follow-up, given that passive monitoring - through morbidity and mortality records - is challenging in settings where records, especially those of morbidity, are incomplete. Other Brazilian cohort studies confirm that, even in our settings, long-term follow-up studies are feasible. For example, the birth cohort from Ribeirão Preto, State of São Paulo 1, begun in 1978, continues to be followed to this date, as does the 1982 cohort from Pelotas, Southern Brazil 2 , regarded as one of the largest and longest birth cohorts in the developing world 3 .

The aim of the present article is to describe the methods of the 2004-2005 follow-up of the 1993 Pelotas (Brazil) birth cohort. It also includes a description of the frequencies of major sociodemographic variables that will be used in subsequent articles of the present supplement. The general aims of the cohort and illustrative results are available from recent publications 4,5 . 


\section{Methods}

All children born in 1993 in the city of Pelotas and whose mothers lived within the city's urban area were eligible for participation in the longitudinal study. Of the 5,265 children born alive in 1993, only 16 mothers could not be interviewed or refused to participate in the study. Subsamples of these children were visited at 1,3 , and 6 months and 1, 4, 6, and 9 years of age. In 2004, all cohort members were sought for a further follow-up, and four sub-studies were carried out in 2005. The overall design of the 1993 Pelotas cohort is presented in Table 1. In the present article, we describe the specific methodology of the 2004-2005 follow-up of the 1993 birth cohort, which took place between July 2004 and March 2005.

\section{Strategy for tracing cohort participants}

As shown in Table 1, after the perinatal follow-up, only sub-samples of the cohort were visited in the remaining follow-ups carried out up to 2004, meaning that almost 4,000 cohort participants were visited only once (perinatal visit) prior to adolescence. Tracing the adolescent subjects in 2004-2005 was therefore an arduous task, especially given the mobility of the target population throughout the 11-year period.

Several search strategies were adopted in order to trace the greatest possible number of adolescents in this follow-up. The general principle was to carry out a household visit based on the most recent address in file. Each of the methods used will be described below.

\section{- Anthropometric school census}

In 2004, all schools in the city of Pelotas were included in an anthropometric study. Although this survey was not officially a part of the 1993 cohort, the same researchers were involved in the two studies. Approximately 24,000 1st to $4^{\text {th }}$ grade elementary school students from private and public schools in the city of Pelotas were measured and weighed. To carry out this study, we obtained lists from schools containing the names of all students enrolled in these grades. In addition to the student's name, these lists also included parents' names, address, telephone,

Table 1

Description of the 1993 Pelotas (Brazil) birth cohort study, follow-ups.

\begin{tabular}{|c|c|c|c|c|c|}
\hline Year & Follow-up & \multicolumn{4}{|c|}{ Sub-studies } \\
\hline \multirow[t]{12}{*}{ 1993-1994 } & Perinatal $(N=5,249)$ : all live & \multicolumn{4}{|c|}{ Ethnographic $(\mathrm{N}=80)$ : sample stratified by mother's schooling and family income } \\
\hline & births & & & & \\
\hline & 1 month $(\mathrm{N}=649): 13 \%$ of live & & & & \\
\hline & births & & & & \\
\hline & 3 months $(N=647)$ : same as & & & & \\
\hline & above & & & & \\
\hline & 6 months $(N=1,414)$ : all low & & & & \\
\hline & birthweight babies $+20 \%$ of & & & & \\
\hline & the remainder (including those & & & & \\
\hline & visited at 1-3 months) & & & & \\
\hline & 1 year $(N=1,363)$ : & & & & \\
\hline & same as above & & & & \\
\hline \multirow[t]{2}{*}{ 1997-1998 } & 4 years $(N=1,273)$ : & Asthma $(N=1,273)$ : all visited & Injuries ( $N=62$ & $50 \%$ of those & Mental health $(N=634)$ : \\
\hline & same as above & at 4 years & visited a & years & $\begin{array}{c}50 \% \text { of those visited } \\
\text { at } 4 \text { years }\end{array}$ \\
\hline 1999 & - & \multicolumn{2}{|c|}{$\begin{array}{c}\text { Oral health }(\mathrm{N}=359): 25 \% \text { of those visited } \\
\text { at } 4 \text { years }\end{array}$} & \multicolumn{2}{|c|}{$\begin{array}{c}\text { Asthma }(N=532): 50 \% \text { of those visited } \\
\text { at } 4 \text { years }\end{array}$} \\
\hline 2002 & - & \multicolumn{4}{|c|}{ Body composition $(N=172)$ : sample stratified by birthweight and weight gain between 1 and 4 years } \\
\hline \multirow[t]{5}{*}{ 2004-2005 } & $11-12$ years $(N=4,452)$ : & Mental health $(\mathrm{N}=634)$ : same & Ethnographic & Oral health & Body composition \\
\hline & all live births & as the 4-years mental health & $(\mathrm{N}=80):$ same & $(N=359)$ & $(N=644):$ all visited \\
\hline & & study & as the 1-year & same as the & at $1-3$ months \\
\hline & & & ethnographic & 6-years oral & \\
\hline & & & study & health study & \\
\hline
\end{tabular}


grade, class, date of birth, and sex. All children born in 1993 detected in this census were then searched in the 1993 birth cohort database. This search strategy led to the identification of approximately 4,300 adolescents from the 1993 cohort.

\section{- Informative pamphlet}

During the anthropometric school census, children born in 1993 received an informative pamphlet on the cohort study, which included the results obtained in previous visits and describing basic eligibility criteria. The pamphlet included a form to be filled out with the subject's name and date of birth, mother's name, address, and telephone. Youths were asked to take the pamphlet home and bring back the filled-out form. Forms were collected and entered in a prize draw. The study team returned to all schools to pick up the filled forms with the updated address. Approximately 1,850 children handed in the form, of which 785 belonged to the cohort.

\section{- City census}

In the second semester of 2004, all households in the city of Pelotas were visited by a team of fieldworkers asking whether anyone in the household had been born in 1982 (the first Pelotas cohort) or 1993. When subjects born in these years were located, the following data was collected: name, date of birth, school, father's name, mother's name at the time of the subjects birth, mother's current name, hospital of birth, detailed address with reference points, and telephone numbers for contact. Based on this information, these names were then searched in the official cohort databases. Using this strategy, we were able to trace 3,254 cohort subjects.

After visiting subjects whose addresses were obtained in the school and household censuses and through the informative pamphlets, beginning in December 2004, further strategies were employed as an attempt to trace the remaining cohort members.

\section{- Four-year follow-up database}

Subjects not yet located were sought in the fouryear follow up database, which included a subsample of 1,273 children. In case the family was not located at the address provided, interviewers were instructed to ask neighbors for information on the family's whereabouts.

\section{- Perinatal study database}

In the perinatal interview, the following identification information was obtained: mother's name, child's name, address, telephone, neighborhood, addresses and telephone numbers of friends and relatives, and parents' place of work, among others. Adolescents still unidentified using the above strategies were searched in this database. A group of fieldworkers was then sent to the subject's 1993 address in an attempt to locate the family, or at least obtain information on their current address. Approximately 700 subjects were sought using this strategy, of which $30 \%$ were traced. We made telephone calls to families who provided a contact number in 1993. We succeeded in locating 141 of the 172 subjects sought using this strategy. This same strategy was also used for locating subjects identified by other means and that had not yet been traced.

\section{- Hospital records}

Some of the city's hospitals have records of patients admitted in 1993. The following information was contained in these registries: date of admission, mother's name, father's name, and address. In early 2005, when over 3,500 children had already been interviewed, these records were reviewed in search of children born in 1993 who reported (based on the city census) being born in Pelotas, in that particular hospital, and who had not yet been identified in the cohort's official database especially due to changes in mother's or subject's name. Approximately 200 cohort members were sought using this strategy, of which 60 were traced.

\section{- Social network}

Beginning in January 2005, a new strategy was employed to locate the children who had not yet been interviewed. After each questionnaire was administered, the interviewers would ask the family or the adolescent whether they knew anyone born in Pelotas in 1993. In case of a positive response, we collected information on address, name, mother's name, and telephone.

\section{- Vacancy central}

The Pelotas public Elementary School network began enrolling students for the 2005 academic year in December 2004. All this information was registered in a "vacancy central" jointly managed by state and municipality. At the time, roughly 1,000 cohort members had not yet been traced. These subjects were sought in the enrollment list 
made available by the "vacancy central," and the adolescent's name, parents' names, address and telephone number, school, and date of birth were obtained.

\section{- Unified National Health System (SUS) records}

SUS registered all families living in the city of Pelotas in 2002-2003. In early 2005, this database was reviewed in search of subjects that had not yet been traced.

\section{- Telephone directory}

The electronic and print versions of the Pelotas telephone directory were used to locate the most recent address of families based on the parents' name and address.

\section{- Mortality follow-up}

The study's official database already included 111 deaths taken place in the first year of life, which had been actively monitored with the purpose of determining the infant mortality coefficient. During later follow-ups, other deaths were identified and recorded. To update this list, we reviewed, in 2004-2005, the Municipal Secretariat of Health's Mortality Information System for the period between 1994 and 2005.

\section{- 2004 cohort}

Three cohort studies are ongoing in the city of Pelotas: 1982, 1993, and 2004. In the 2004 cohort database, we searched for mothers how had also had children in 1993. This strategy was only employed in the last three months of fieldwork (beginning in January 2005), in search of children not yet traced at the time. We obtained updated identification and address data for subjects traced in this manner.

\section{- Search for institutionalized children}

Based on information obtained from friends and relatives, we found that a number of children born in 1993 had been admitted to institutions for minors and were thus no longer living with their families. Such institutions were searched in an attempt to trace these adolescents.

\section{- Media}

The study was reported in the media (newspaper and radio) in order to emphasize the importance of the participation of all cohort members. This strategy also aimed at facilitating access of interviewers to families.

Figure 1 presents the chronological order of search strategies.

\section{Questionnaires}

The 2004-2005 follow-up questionnaire was divided into four large blocks. Administration of the full questionnaire, including all measurements, took on average 70 minutes.

\section{- Identification block}

This block comprised 53 questions, and was answered by the mother or guardian. Its primary aim was to collect detailed identification data so as to facilitate tracing in future follow-ups. The information recorded included subject's, mother's and father's full names (birth names or otherwise), subject's date of birth, current and future address (for families planning to move), telephone number, neighborhood, and nearby reference points. In addition, the addresses and telephone numbers of friends, relatives, and coworkers of the subject's parents were also recorded.

\section{- Mother's block}

This block comprised 212 questions, and was also administered to the mother or guardian. It included questions on family composition, the subject's academic standing, parents' employment status, family income, ownership of household appliances, number of people in the household, mother's beliefs, fears, and religious persuasion, administration of family financial resources, mother's social routine, subject's raising, family health, parental smoking and alcohol intake, mother's physical activity status, subject's general and oral health conditions, occurrence of bone fractures, age at menarche (among girls), occurrence of hospitalization, medication intake, mental health, and mother's body mass in$\operatorname{dex}(\mathrm{BMI})$.

\section{- Adolescent's block}

This block comprised 114 questions, and was answered by the cohort member. It included questions on school attendance, physical activity, daily leisure routine, work, sleep, dietary habits, dieting, oral health, time spent with family, and self-perceived wellbeing and nutritional status. 
Figure 1

Chronological sequence of strategies used to trace members of the 1993 Pelotas (Brazil) birth cohort study, in the $2004-2005$ follow-up.

\begin{tabular}{|c|c|c|c|c|c|c|c|c|c|c|}
\hline May/04 & Jun/04 & Jul/04 & Aug/04 & Sep/04 & Oct/04 & Nov/04 & $\mathrm{Dec} / 04$ & Jan/05 & $\mathrm{Feb} / 05$ & Mar/05 \\
\hline & & \multicolumn{9}{|c|}{ Anthropometric school census (pamphlet) } \\
\hline & & \multicolumn{9}{|c|}{ Household visits 1993 cohort } \\
\hline & & \multicolumn{9}{|c|}{ City census } \\
\hline & & & & & & Campai & schools & & & \\
\hline & & & & & & \multicolumn{5}{|c|}{ Telephone calls } \\
\hline & & & & & & & \multicolumn{4}{|c|}{ Perinatal study and 4-year follow-up databases } \\
\hline & & & & & & & \multicolumn{4}{|c|}{ Vacancy central } \\
\hline & & & & & & & \multicolumn{4}{|c|}{ Hospital records } \\
\hline & & & & & & & \multicolumn{4}{|c|}{ Telephone directory } \\
\hline & & & & & & & \multicolumn{4}{|c|}{ Social network } \\
\hline & & & & & & & \multicolumn{4}{|c|}{ Unified National Health System (SUS) records } \\
\hline & & & & & & & \multicolumn{4}{|c|}{1982 and 2004 cohorts } \\
\hline & & & & & & & \multicolumn{4}{|c|}{ Search for institutionalized children } \\
\hline
\end{tabular}

\section{- Confidential block}

This block comprised 66 questions, and was answered confidentially by the cohort member, unaided by others. It included information on smoking, alcohol and drugs, fighting and violence, family activities, knowledge of AIDS and other sexually transmissible diseases, relationship with parents, and the adolescent's mental health.

\section{Interviewers}

Interviewer recruitment was carried out basically in two ways: (a) searching the interviewer database of the Center for Epidemiological Research, Federal University in Pelotas for interviewers with previous experience from other studies; and (b) contacting the National Employment System (SINE) in search of persons with the following characteristics: minimum age 18 years, complete secondary education, female, available 8 hours per workday. We also provided information on remuneration ( $\mathrm{R} \$ 10.00$ per interview).

Recruited candidates were interviewed by the research team. Those fulfilling the desired prerequisites (responsible, able to express themselves verbally, serious, congenial, punctual) were selected for a training period. The planned number of interviewers for fieldwork was 18. Due to drop-outs and dismissals during the course of fieldwork, the interviewer selection process was repeated numerous times. All selected candidates underwent specific measurement training.

Interviewers were submitted to a theoretical and practical training period of approximately 40 hours, which included reading the questionnaire and instruction manual in full, simulated questionnaire administration among the candidates themselves, and interviews with mothers and adolescents (excluding those born in 1993). Candidates who successfully completed this training were selected as full or substitute interviewers, depending on the number of positions available.

\section{Measurement training}

Several measurements were obtained during the home interview, including arterial pressure, weight, height, and skinfold thickness (tricipital and subscapular). Interviewers were trained and standardized by calculating the technical error of measurement (TEM), based on values published by the National Centers for Health Statistics (NCHS) in 1977 6. On a monthly basis, interviewers were re-standardized in performing these measurements, and were retrained when necessary. Up to three standardization sessions were carried out with interviewers who could not achieve the quality level required. In case the interviewer was unable to obtain acceptable measurements after three attempts, she was dismissed. 


\section{Quality control}

Three aspects were prioritized in this evaluation: (a) determining the family's level of satisfaction with the interviewer, to ensure the family's participation in future visits; (b) identifying potential work fraud by interviewers; (c) testing the repeatability of key items in the questionnaire.

To this end, two strategies were employed: (a) about $10 \%$ of participants visited in 20042005 were visited a second time, when a short form of the questionnaire was administered; (b) a sample of $40 \%$ of remaining participants with access to a telephone landline were called, and the short questionnaire was administered by telephone.

\section{Reversion of refusals}

A number of families refused to take part in the study after the first contact was made by the interviewer. These families were re-visited at least twice more on different days and times. In case the refusal was not reverted, one of the field coordinators made a telephone call to the family with to clarify the goals of the study and the importance of the participation of all cohort members. On rare occasions when refusal persisted, a researcher made a last attempt either by phone or in person. The final number of refusals was 30 .

\section{Ethical aspects}

The 2004-2005 follow-up was approved by the research ethics committee of the School of Medicine, Federal University in Pelotas. Parents or guardians signed a term of free informed consent authorizing children to participate in the study. Data used in the different tracing strategies were always restricted to researchers, and personal data remained confidential.

\section{Variables and definitions}

The articles included in the present supplement address different areas of adolescent health and behavior. Study outcomes refer to the 2004-2005 follow-up and their methodological aspects are described in the corresponding articles.

The independent variables investigated, which refer to both early and contemporary exposures, are common to the various articles. Due to the diversity of the studied outcomes, in some articles we evaluated only early or only contemporary exposures, whereas in others both types of variables were considered. Below, we briefly describe the operationalization and content of major variables.
Regarding early variables, family income was collected in the currency of the time (Cruzado Novo - NCz\$, from 1 January to 15 March ; Cruzeiro-Cr\$, from 16 March to 31 July; and Cruzeiro Real-CR\$, from 1 August to the end of the year) and subsequently converted to and categorized by minimum wages. Given the intense inflation in Brazil during that period, data were converted into minimum wages at the end of each week of fieldwork. Smoking and alcohol intake by the mother during pregnancy were defined as any use of cigarettes or alcohol at any moment in the gestational period. Low birthweight was defined as birth weight below 2,500g. Preterm birth was defined as gestational age under 37 weeks. Exclusive or predominant breastfeeding was defined as breast milk intake, exclusively or in addition to other liquids (water, tea, or juice); exclusive breastfeeding was extremely rare in 1993, and the small number of children in this category prevents statistical analyses.

Regarding the demographic and socioeconomic variables collected during the 2004-2005 follow-up, skin color was measured using the procedure adopted $b$ the Brazilian Institute for Geography and Statistics (IBGE): adolescents classified their skin color as white, black, brown (or mixed), yellow (East Asian), or indigenous (cor branca, preta, parda, amarela ou indígena). For analysis purposes, the categories "black" and "brown" were grouped, and categories "yellow" and "indigenous," due to their low frequency, were considered only for adjustment purposes, being omitted from the results. Mother's schooling was collected in completed years of study, and later grouped into four categories. The "assets index" variable (in quintiles) was constructed based on principal components analysis of the ownership of a series of domestic goods (color television, radio, car, vacuum cleaner, washing machine, VCR/DVD, sound system, computer, Internet access, refrigerator, freezer) and characteristics of the residence (number and type of bathrooms, piped water, number of rooms used for sleeping, presence of a maid, construction material, and whether the house was owned, rented, or loaned) 7 . For analysis purposes, we used only the first factor of the principal component analysis, which was able to explain $30 \%$ of the variance in the model, divided into quintiles (from poorest to richest).

Regarding contemporary nutritional and behavioral variables, maternal BMI was calculated based on the mother's weight and height. The variable "adolescent's nutritional status" was generated according to World Health Organization $(\mathrm{WHO})$ recommendations 8 . Nutritional categories adopted in the study were as follows: thin 
(BMI/sex/age $\leq$ percentile 5), normal (P5 > IMC $<$ P95), at risk of overweight (IMC $\geq \mathrm{P} 85$ and one or both skinfolds $\leq$ P90), and obese (IMC $\geq$ P85 and both skinfolds $\geq$ P90). The anthropometric reference used was that of the NCHS 9. The variable "self-perceived weight" refers to how the adolescent feels about his or her weight: too thin, thin, normal, fat, or very fat. For the definition of a diet poor in fiber and rich in fat, we used the Block food frequency questionnaire 10 . This questionnaire attributes frequency of intake points based on a list of foods defined in the instrument. A score below 20 in fiber-rich foods characterizes a diet poor in this nutrient, whereas a fat-rich diet corresponds to a score greater than 27 for foods rich in fat. Sedentariness was defined as a score below 300 minutes of physical activity per week. This criterion is in accordance with the recommendation of 60 minutes per day, currently valid for children and adolescents 11 . We considered both leisure activities and transportation to school. We considered as a repeating student any adolescent that failed any school year at least once. Adolescents who worked outside home or in a family business were classified as workers.

\section{Statistical analysis}

In all articles that used variables from the 6-months or 1 or 4-years follow-ups, analyses were weighted to compensate for the oversampling of low birthweight children in these visits. This was necessary because all children born with low birthweight were included in these follow-ups. The articles included in this supplement describe the specific details of their particular statistical analyses.

\section{Results}

Of the 5,249 children born in 1993, 141 were located in SIM. Of the remaining 5,108, 4,452 were interviewed, which, when added to the deaths, represent a follow-up rate of $87.5 \%$. Though the percentage of follow-up was significantly different among certain subgroups (Table 2), the magnitude of these differences was small.

The distribution of the major exposure variables is presented in Table 3 (early factors) and Table 4 (contemporary factors), both for

\section{Table 2}

Follow-up rates in the 2004-2005 follow-up of the 1993 Pelotas (Brazil) birth cohort study, according to baseline characteristics.

\begin{tabular}{|c|c|c|c|}
\hline Variable & Original number (1993) & Percentage interviewed (2004-2005) * & $\mathrm{p}$-value ** \\
\hline Sex & 5,248 & & 0.234 \\
\hline Male & 2,606 & 87.0 & \\
\hline Female & 2,642 & 88.0 & \\
\hline Family income (minimum wages) & 5,249 & & $<0.001$ \\
\hline$\leq 1$ & 967 & 88.2 & \\
\hline $1.1-3.0$ & 2,260 & 88.7 & \\
\hline $3.1-6.0$ & 1,204 & 89.0 & \\
\hline $6.1-10.0$ & 433 & 79.9 & \\
\hline$>10.0$ & 385 & 82.6 & \\
\hline Mother's schooling (years) & 5,246 & & $<0.001$ \\
\hline 0 & 134 & 82.1 & \\
\hline $1-4$ & 1,338 & 88.6 & \\
\hline $5-8$ & 2,424 & 89.9 & \\
\hline$\geq 9$ & 1,350 & 82.5 & \\
\hline Birthweight (g) & 5,232 & & 0.126 \\
\hline$<2,500$ & 510 & 90.0 & \\
\hline $2,500-3,499$ & 3,361 & 86.9 & \\
\hline$\geq 3,500$ & 1,361 & 87.9 & \\
\hline Gestational age (weeks) & 5,193 & & 0.192 \\
\hline$<37$ & 611 & 89.2 & \\
\hline$\geq 37$ & 4,582 & 87.3 & \\
\hline
\end{tabular}

(continues) 
Table 2 (continued)

\begin{tabular}{lccc}
\hline Variable & Original number (1993) & Percentage interviewed (2004-2005) * & $\mathrm{p}$-value $^{* *}$ \\
\hline Weight-for-length (Z-scores) & 4,947 & & 0.886 \\
$<-2$ & 179 & 88.3 & \\
Between -2 and +2 & 4,572 & 87.2 & \\
$>+2$ & 196 & 87.8 & 0.978 \\
Length-for-age (Z-scores) & 5,118 & & \\
$<-2$ & 551 & 87.1 & \\
Between -2 and +2 & 4,509 & 87.4 & 0.059 \\
$>+2$ & 58 & 87.9 & \\
Weight-for-age (Z-scores) & 5,189 & & \\
$<-2$ & 448 & 90.9 & - \\
Between -2 and +2 & 4,679 & 87.1 & \\
$>+2$ & 62 & 90.3 & 87.5 \\
Total & 5,249 & & \\
\hline
\end{tabular}

* Subjects who had died were considered as traced;

** Chi-squared test.

Table 3

Description of the major early exposures used in the articles of the 1993 Pelotas (Brazil) birth cohort study, $2004-2005$ followup supplement (data collected in 1993).

\begin{tabular}{|c|c|c|c|c|c|c|}
\hline \multirow[t]{2}{*}{ Variable } & \multicolumn{2}{|c|}{ Total } & \multicolumn{2}{|c|}{ Boys } & \multicolumn{2}{|c|}{ Girls } \\
\hline & $\mathrm{n}$ & $\%$ & $\mathbf{n}$ & $\%$ & $\mathbf{n}$ & $\%$ \\
\hline Family income (minimum wages) & 5,137 & - & 2,550 & - & 2,586 & - \\
\hline$\leq 1$ & 967 & 18.8 & 488 & 19.1 & 478 & 18.5 \\
\hline $1.1-3$ & 2,160 & 42.0 & 1,087 & 42.6 & 1,073 & 41.5 \\
\hline $3.1-6$ & 1,205 & 23.5 & 572 & 22.4 & 633 & 24.5 \\
\hline $6.1-10$ & 420 & 8.2 & 205 & 8.1 & 215 & 8.3 \\
\hline$>10$ & 385 & 7.5 & 198 & 7.8 & 187 & 7.2 \\
\hline Mother smoked during pregnancy & 5,249 & - & 2,606 & - & 2,642 & - \\
\hline No & 3,497 & 66.6 & 1,763 & 67.7 & 1,733 & 65.6 \\
\hline Yes & 1,752 & 33.4 & 843 & 32.3 & 909 & 34.4 \\
\hline Mother drank alcohol during pregnancy & 5,249 & - & 2,606 & - & 2,642 & - \\
\hline No & 4,982 & 94.9 & 2,482 & 95.2 & 2,499 & 94.6 \\
\hline Yes & 267 & 5.1 & 124 & 4.8 & 143 & 5.4 \\
\hline Low birthweight & 5,232 & - & 2,598 & - & 2,634 & - \\
\hline No & 4,722 & 90.2 & 2,372 & 91.3 & 2,350 & 89.2 \\
\hline Yes & 510 & 9.8 & 226 & 8.7 & 284 & 10.8 \\
\hline Preterm & 5,171 & - & 2,573 & - & 2,598 & - \\
\hline No & 4,582 & 88.6 & 2,287 & 88.9 & 2,295 & 88.3 \\
\hline Yes & 589 & 11.4 & 286 & 11.1 & 303 & 11.7 \\
\hline Predominant breastfeeding (months) * & 1,428 & - & 689 & - & 739 & - \\
\hline $0-0.9$ & 512 & 35.8 & 268 & 38.9 & 243 & 32.8 \\
\hline $1-1.9$ & 273 & 19.1 & 121 & 17.5 & 152 & 20.6 \\
\hline $2-2.9$ & 188 & 13.2 & 84 & 12.3 & 104 & 14.1 \\
\hline $3-3.9$ & 262 & 18.4 & 116 & 16.8 & 147 & 19.9 \\
\hline 4 or more & 193 & 13.5 & 100 & 14.5 & 93 & 12.6 \\
\hline
\end{tabular}

* Frequencies are weighted due to overrepresentation of low birthweight children. 
the entire cohort and for each sex. In 1993, the family income of less than half the mothers was above three minimum wages; one third of mothers smoked during pregnancy; and $5 \%$ of mothers reported drinking alcohol when pregnant (Table 3). Among children included in the cohort, approximately $10 \%$ were born with low birthweight and $11 \%$ were preterm. Only one in three children was exclusively or predominantly breastfed for three months or longer.

In the 2004-2005 follow-up (Table 4), half the subjects traced were boys, keeping the proportion found at birth, and about two-thirds of subjects had white skin. About $30 \%$ of mothers had completed elementary education, and about $20 \%$ were obese. Regarding the adolescent's nutritional status, almost a quarter of subjects were overweight, and a similar proportion considered themselves to be fat. Prevalence of fiber-poor and fat-rich diets was $84 \%$ and $37 \%$, respectively, with no difference in terms of sex. On the other hand, prevalence of sedentariness was higher among girls (68\%) than among boys (49\%). One in three adolescents had failed school at least once, whereas less than $5 \%$ worked at age 11 years.

\section{Discussion}

The Pelotas cohorts (1982, 1993, and 2004), in conjunction with other Brazilian prospective studies 1, demonstrates the feasibility of longterm follow-ups in our settings. The major challenge of the 2004-2005 follow-up was to locate cohort members that, in their majority, had not been seen since the hospital visit shortly after birth. Accomplishing this task meant resorting to a series of search strategies for tracing adolescents and their families. Adolescents visited in 2004-2005 are again being interviewed since 2008, and the results of this follow-up started to become available in 2009 .

With regard to the follow-up rate, we considered the percent of subjects traced in 2004-2005 as substantial $(87.5 \%)$, considering that the only other time the full cohort was interviewed was on occasion of the perinatal study, in 1993. In comparison to other Brazilian cohorts, our follow-up rate was very high. For example, in the cohort studies carried out in Ribeirao Preto, Southeastern Brazil 1, follow-up rates at ages 8-10 years and $10-11$ years were $42 \%$ and $32 \%$, respectively. Similarly, in the cohort from São Luis, in Northeastern Brazil, $35 \%$ on subjects were traced at age 7-9 years 1 .

The proportion of traced subjects was similar for both sexes (Table 2), however, there was a higher proportion of losses among adolescents from higher-income families ( $>6$ minimum wages) and in the extreme categories of

Table 4

Description of major contemporary exposures used in the articles of the 1993 Pelotas (Brazil) birth cohort study, $2004-2005$ follow-up supplement (data collected in 2004-2005).

\begin{tabular}{|c|c|c|c|c|c|c|}
\hline \multirow[t]{2}{*}{ Variable } & \multicolumn{2}{|c|}{ Total } & \multicolumn{2}{|c|}{ Boys } & \multicolumn{2}{|c|}{ Girls } \\
\hline & $\mathrm{n}$ & $\%$ & $\mathrm{n}$ & $\%$ & $\mathbf{n}$ & $\%$ \\
\hline Sex & 4,452 & - & 2,192 & - & 2,260 & - \\
\hline Male & 2,192 & 49.2 & - & - & - & - \\
\hline Female & 2,260 & 50.8 & - & - & - & - \\
\hline Skin color & 4,420 & - & 2,170 & - & 2,250 & - \\
\hline White & 2,953 & 66.8 & 1,481 & 68.2 & 1,472 & 65.4 \\
\hline Black or brown & 1,259 & 28.5 & 587 & 27.1 & 672 & 29.9 \\
\hline Yellow or indigenous & 208 & 4.7 & 102 & 4.7 & 106 & 4.7 \\
\hline Mother's schooling (years) & 4,414 & - & 2,174 & - & 2,240 & - \\
\hline $0-4$ & 1,145 & 25.9 & 567 & 26.1 & 578 & 25.8 \\
\hline $5-8$ & 1,901 & 43.1 & 922 & 42.4 & 979 & 43.7 \\
\hline $9-11$ & 947 & 21.5 & 475 & 21.8 & 472 & 21.1 \\
\hline 12 or more & 421 & 9.5 & 210 & 9.7 & 211 & 9.4 \\
\hline
\end{tabular}

(continues) 
Table 4 (continued)

\begin{tabular}{|c|c|c|c|c|c|c|}
\hline \multirow[t]{2}{*}{ Variable } & \multicolumn{2}{|c|}{ Total } & \multicolumn{2}{|c|}{ Boys } & \multicolumn{2}{|c|}{ Girls } \\
\hline & $\mathrm{n}$ & $\%$ & $\mathrm{n}$ & $\%$ & $\mathrm{n}$ & $\%$ \\
\hline Assets index (quintiles) & 4,284 & - & 2,111 & - & 2,173 & - \\
\hline 1st (lowest) & 863 & 20.1 & 445 & 21.1 & 418 & 19.2 \\
\hline $2^{\text {nd }}$ & 851 & 19.9 & 414 & 19.6 & 437 & 20.1 \\
\hline 3 rd & 857 & 20.0 & 400 & 18.9 & 457 & 21.0 \\
\hline $4^{\text {th }}$ & 857 & 20.0 & 415 & 19.7 & 442 & 20.3 \\
\hline $5^{\text {th }}$ & 856 & 20.0 & 437 & 20.7 & 419 & 19.3 \\
\hline Mother's BMI $\left(\mathrm{kg} / \mathrm{m}^{2}\right)$ & 4,141 & - & 2,034 & - & 2,107 & - \\
\hline$\leq 18.5$ & 69 & 1.7 & 36 & 1.8 & 33 & 1.5 \\
\hline 18.5 to 24.9 & 1,727 & 41.7 & 857 & 42.1 & 870 & 41.3 \\
\hline 25.0 to 29.9 & 1,410 & 34.0 & 671 & 33.0 & 739 & 35.1 \\
\hline$\geq 30.0$ & 935 & 22.6 & 470 & 23.1 & 465 & 22.1 \\
\hline Nutritional status & 4,442 & - & 2,186 & - & 2,256 & - \\
\hline Thin & 313 & 7.0 & 140 & 6.4 & 173 & 7.7 \\
\hline Eutrophic & 3,100 & 69.8 & 1,497 & 68.5 & 1,603 & 71.1 \\
\hline Risk of overweight & 514 & 11.6 & 220 & 10.1 & 294 & 13.0 \\
\hline Obese & 515 & 11.6 & 329 & 15.0 & 186 & 8.2 \\
\hline Very thin & 144 & 3.2 & 60 & 2.8 & 84 & 3.7 \\
\hline Self-perceived weight & 4,430 & - & 2,175 & - & 2,255 & - \\
\hline Thin & 716 & 16.2 & 364 & 16.7 & 352 & 15.6 \\
\hline Normal & 2,457 & 55.5 & 1,280 & 58.8 & 1,177 & 52.2 \\
\hline Fat & 913 & 20.6 & 402 & 18.5 & 511 & 22.7 \\
\hline Very fat & 200 & 4.5 & 69 & 3.2 & 131 & 5.8 \\
\hline Fiber-poor diet & 4,446 & - & 2,186 & - & 2,260 & - \\
\hline No & 714 & 16.1 & 342 & 15.6 & 372 & 16.5 \\
\hline Yes & 3,732 & 83.9 & 1,844 & 84.4 & 1,888 & 83.5 \\
\hline Fat-rich diet & 4,443 & - & 2,185 & - & 2,258 & - \\
\hline No & 2,817 & 63.4 & 1,382 & 63.3 & 1,435 & 63.6 \\
\hline Yes & 1,626 & 36.6 & 803 & 36.7 & 823 & 36.4 \\
\hline Sedentariness & 4,289 & - & 2,117 & - & 2,170 & - \\
\hline No & 1,793 & 41.8 & 1,088 & 51.4 & 704 & 32.4 \\
\hline Yes & 2,496 & 58.2 & 1,029 & 48.6 & 1,466 & 67.6 \\
\hline Academic failure & 4,331 & - & 2,125 & - & 2,206 & - \\
\hline Never & 2,760 & 63.7 & 1,216 & 57.2 & 1,544 & 70.0 \\
\hline Once & 947 & 21.9 & 519 & 24.4 & 428 & 19.4 \\
\hline More than once & 624 & 14.4 & 390 & 18.4 & 234 & 10.6 \\
\hline Work & 4,441 & - & 2,183 & - & 2,258 & - \\
\hline No & 4,248 & 95.6 & 2,061 & 94.4 & 2,187 & 96.9 \\
\hline Yes & 193 & 4.4 & 122 & 5.6 & 71 & 3.1 \\
\hline
\end{tabular}

BMI: body mass index.

mother's schooling ( 0 and $\geq 9$ years). There was no significant difference with respect to birthweight, gestational age, and anthropometric indicators at birth (weight-for-length, length-forage, weight-for-age). It should be noted that we interviewed at least $80 \%$ of adolescents in each group investigated.

Reaching such a high follow-up rate was an arduous task. Initially, a series of search strate- gies was employed to compensate for the lack of continuous monitoring of the addresses of cohort members. At 11 years of age, the school and city censuses were the most successful strategies for tracing these adolescents. We suggest that future cohort studies be extremely careful with identification data. We recommend that contact with families and/or youngsters be made every year, through birthday cards, internet pages or 
communities, periodic phone calls for updating address information, and newspaper articles on the cohort study.

Finally, we highlight the fact that, in spite of the difficulties involved, especially those related to tracing participants and to high cost, it is pos- sible to carry out long-term prospective studies in Brazil. The richness of the information that is obtained in studies of this type justifies the planning of other cohorts in the country, both birth cohorts and cohorts of subjects at other ages at the beginning of the study.

\section{Resumo}

O objetivo deste artigo é descrever a metodologia do acompanhamento realizado em 2004-2005 da coorte de nascidos em 1993 na cidade de Pelotas, Rio Grande do Sul, Brasil. Todas as crianças nascidas em 1993 nessa cidade, cujas mães residiam no município, foram elegíveis para um estudo longitudinal. Entre os meses de julho de 2004 e março de 2005, todos os participantes da coorte foram procurados para um acompanhamento. Diversas estratégias de busca foram utilizadas para auxiliar na localização dos participantes, sendo as principais um censo em todas as escolas do município e um censo domiciliar. O Sistema de Informações sobre Mortalidade foi monitorado para detecção de óbitos de participantes da coorte. Dos 5.249 participantes da coorte, 4.452 foram entrevistados em 2004 2005, os quais, somados aos 141 óbitos detectados, representam 87,5\% da coorte original. Apesar das dificuldades logísticas e financeiras, é possível realizar estudos prospectivos com altas taxas de acompanhamento em longo prazo no contexto brasileiro.

Metodologia; Estudos Prospectivos; Estudos de Coortes

\section{Contributors}

P. C. Hallal and A. M. B. Menezes coordinate the 1993 birth cohort and approved the final version of the manuscript. C. L. Araújo led the writing of the manuscript and coordinates the 1993 birth cohort. M. F. A. Vieira, M. B. Neutzling, H. Gonçalves, and L. Anselmi coordinated fieldwork in the 2004-2005 follow-up of the 1993 cohort and approved the final version of the manuscript. S. C. Dumith led data analysis and approved the final version of the manuscript.

\section{Acknowledgments}

The cohort study is supported by the Wellcome Trust. The initial phases of the cohort study were funded by the European Union, the Brazilian National Program for Centers of Excellence (PRONEX), the National Research Council (CNPq), and the Brazilian Ministry of Health. The first author thanks CNPq for support in form of a study grant. 


\section{References}

1. Cardoso VC, Simões VM, Barbieri MA, Silva AA, Bettiol H, Alves MT, et al. Profile of three Brazilian birth cohort studies in Ribeirão Preto, SP and São Luis, MA. Braz J Med Biol Res 2007; 40:1165-76.

2. Victora CG, Barros FC. Cohort profile: the 1982 Pelotas (Brazil) birth cohort study. Int J Epidemiol 2006; 35:237-42.

3. Harpham T, Huttly S, Wilson I, Wet T. Linking public issues with private troubles: panel studies in developing countries. J Int Dev 2003; 15:353-63.

4. Victora CG, Araújo CLP, Menezes AMB, Hallal PC, Vieira MF, Neutzling MB, et al. Methodological aspects of the 1993 Pelotas (Brazil) birth cohort study. Rev Saúde Pública 2006; 40:39-46.

5. Victora CG, Hallal PC, Araújo CL, Menezes AMB, Wells JC, Barros FC. Cohort profile: the 1993 Pelotas (Brazil) birth cohort study. Int J Epidemiol 2008; 37:704-9.

6. Cameron N. Reliability. In: Cameron N, editor. The measurement of human growth. London: Croom Helm; 1984. p. 100-12.
7. Filmer D, Pritchett LH. Estimating wealth effects without expenditure data: or tears: an application to educational enrollments in states of India. Demography 2001; 38:115-32.

8. World Health Organization. WHO Expert Committee on Physical Status: the use and interpretation of anthropometry. Geneva: World Health Organization; 1995. (WHO Technical Report Series, 854).

9. Must A, Dallal GE, Dietz WH. Reference data for obesity: 85th and 95th percentiles of body mass index (wt/ht2) and triceps skinfold thickness. Am J Clin Nutr 1991; 53:839-46.

10. Block G. Improving diet methods, improving epidemiologic methods. Ann Epidemiol 1994; 4:257-8.

11. Strong WB, Malina RM, Blimkie CJ, Daniels SR, Dishman RK, Gutin B, et al. Evidence based physical activity for school-age youth. J Pediatr 2005; 146:732-7.

Submitted on $03 / \mathrm{Feb} / 2009$

Approved on 10/Aug/2009 